\title{
«MALLORCA», UN POEMA EN EL OLVIDO DE JORGE LUIS BORGES
}

\author{
POR \\ CARLOS MENESES \\ Palma, Mallorca
}

Borges, tan acostumbrado a sorprender, tan convencido de que no existe ayer, hoy y mañana, que todo se halla en una misma esfera llamada tiempo, y en la que los humanos vagamos como microscópicos cuerpos sin órbita, ha escrito sobre todo lo que conocieron sus ojos (en años en que le fue posible utilizarlos) y sus otros sentidos cuando les fue obligado asumir la ausencia de la vista, sobre todo cuanto le ha significado motivo de emoción o razonamiento, motivo de misterio a desentrañar. Ninguna persona que le haya resultado interesante ha escapado de ser incluida en su gigantesco universo, ningún hecho considerable como ningún lugar de los que ha visitado se ha quedado sin plaza en su brillante literatura. A veces el nombre de una ciudad o la fecha de un acontecimiento emerge tardíamente en la rica historia de su deambular en tinieblas, pero emerge, y la impuntualidad no es achacable a él, sino a circunstancias fortuitas, a motivos determinados por ese monstruo, tan poderoso como él, que se conoce bajo el nombre de destino.

Por eso algunos poemas, algunas páginas escritas en juventud o en madurez se quedaron desconectadas de su creador, encerradas en la mazmorra amarillenta de viejas publicaciones diarias o semanales, prisioneras sempiternamente del olvido, escondidas en esos fríos cementerios de papel a los que acuden estudiosos y curiosos. En una hemeroteca palmesana es posible hallar un poema, posiblemente el último de sus desconocidas producciones mallorquinas, puesto que en años anteriores han sido descubiertas otras que aparecieron en revistas de la isla. Se trata de un poema en prosa, que, tras esa publicación, no vio ninguna otra, y todo lo que encerraba fue hurtado al conocimiento de quienes siguen y analizan obra y personalidad del gran escritor y poeta recientemente desaparecido. $\mathrm{He}$ aquí dicho texto: 
Mallorca es un lugar parecido a la felicidad, apto para en él ser dichoso, apto para escenario de dicha, y yo - como tantos isleños y forasteros- no he poseído casi nunca el caudal de felicidad que uno debe llevar adentro para sentirse espectador digno (y no avergonzado) de tanta claridad de belleza. Dos veces he vivido en Mallorca y mi recuerdo de ella es límpido y quieto: unas tenidas discutidoras con los amigos, una caminata madrugadora que empezó en Valldemosa y se cansó en Palma, una niña rosa y dorada de la que estuve enamorado tal yez y a la que no se lo dije nunca, unos días largos remansándose en el cálculo de las playas. Ahora dejo de escribir y sigo acordándome.

(El Día, Palma de Mallorca, 21-XI-1926.)

JORGe LUIS BORgeS

Es difícil precisar la fecha y el lugar donde fue escrito este breve texto que 1leva por título «Mallorca». Como es también complicado descubrir cómo llegó a las páginas de El Día ${ }^{1}$. Es de suponer que esas líneas poéticas las escribió después de su segunda visita a la isla y que las envió a su mejor amigo de juventud, el poeta mallorquín Jacobo Sureda, quien, a la sazón, se hallaba en Alemania. Esto debió haber ocurrido en 1923, y solamente tres años más tarde, Sureda, que retorna a Mallorca tras haber publicado el que sería su único libro de poemas, El prestidigitador de los cinco sentidos, entrega el pequeño texto de su amigo argentino a otro poeta mallorquín, encargado de la página literaria de los domingos en el diario mencionado, Miguel Angel Colomar. Y el poema se publica sin ningún dato del autor, como tampoco motiva comentarios posteriores.

«Mallorca» es una apretada síntesis de lo que la isla representó para el poeta, de lo que el conjunto de días que pasó en ella le dejaron en la memoria, de las huellas indelebles que quedaron en su espíritu. No habían sido visitas propiamente las que realizó; habían sido residencias, sobre todo la primera, entre 1920 y 1921. Alrededor de ocho meses, viviendo con su familia —el padre sólo los acompañó un mes y regresó a Buenos Aires - primero en un hotel palmesano, después en la casona de los Sureda, en la pequeña población de Valldemosa. Ocho meses durante los que no actuó como el turista clásico ni como el visitante que ve ese nuevo mundo como si estuviera contemplando un cuadro. En ese tiempo trabó

${ }^{1}$ El diario El Día se publicó hasta abril de 1939, y el poema de Borges apareció el 21 de noviembre de 1926, en la primera página del domingo, que era la destinada a los artículos literarios y de opinión. 
amistades, influyó poderosamente en los jóvenes poetas mallorquines, a los cuales llegó portador del bagaje ultraísta, tan de moda por esos tiempos, sobre todo en Madrid. Tanto él como su madre y su hermana Norah tuvieron una vida activa, pues esta última pintó dos murales, uno en el hotel de Palma - situado en la calle San Miguel- donde vivían y otro en una casa de Valldemosa, que aún lo conserva.

Sobre su primera visita, él mismo ha hecho declaraciones y ha escrito algunas páginas recordándola. En cambio, la segunda, que fue breve y debió de ocurrir en 1923, había quedado totalmente olvidada. De vez en cuando, al rememorar el ir y venir de Borges por el mundo, solamente los biógrafos muy prolijos apuntan esa segunda estancia en la mayor de las Baleares ${ }^{2}$.

Pero si durante la primera estancia, más distendida, más larga, dio la sensación de un embajador del ultraísmo enviado a Mallorca por Cansinos Asséns, durante la segunda vez que llega a la isla no publica nada (puesto que el poema que comentamos debió de ser escrito ya en Buenos Aires y apareció tres años después) y prácticamente pasa inadvertido. Es ya año en que el ultraísmo - que ha declinado casi totalmente- ha dejado de interesarle, en que quiere demostrar que no es "proclive a esas prácticas», aunque en algunos de sus versos de Fervor de Buenos Aires aún se encuentren ligeras huellas de su paso por esa controvertida corriente poética ${ }^{3}$.

El poema que comentamos acusa, en primer término, un gran sentido de condensación. Es una confesión, la confesión de cómo recuerda Mallorca, en apunte que trazó, quién sabe, pensando en una ampliación posterior. Es una mirada terriblemente adulta para un joven de veinticuatro años, en la que entremezcla, con evidente fruición, lo íntimo y la belleza del lugar, la impresión que le causa el paisaje y sus gentes, con su rea-

${ }^{2}$ En 1971 Borges escribía: «Fuimos a Mallorca porque era barata y hermosa y difícilmente habría más turistas que nosotros. Vivimos casi un año en Palma y Valldemosa, una aldea en lo alto de las colinas. Seguí aprendiendo latín, ahora bajo la tutela de un sacerdote, quien me contó que, como su propia imaginación le bastaba para sus necesidades, nunca intentó leer una novela.» Este párrafo, perteneciente a unos extensos apuntes sobre su vida, fue publicado en The New Yorker bajo el título de «Autobiographical notes», el 19 de septiembre de 1970. Traducido al castellano por José E. Pacheco, apareció en La Gaceta, octubre de 1971, número 10 (México: Fondo de Cultura Económica). Se refiere únicamente a su primera estancia.

${ }^{3}$ En carta dirigida a su amigo Jacobo Sureda, en agosto de 1922, le anuncia que en septiembre marchará hacia Europa. E1 motivo era la operación de cataratas de su padre, que se realizó en Suiza. Jorge Luis aprovechó para recorrer las ciudades donde había vivido, y una de ellas fue Palma de Mallorca. 
lidad espiritual, con su visión de la vida. En esa breve manifestación borgeano-mallorquina afloran estados de ánimo y, sobre todo, se descubren constantes en su comportamiento: «y yo [...] no he poseído casi nunca el caudal de felicidad que uno debe llevar adentro para sentirse espectador digno $[\ldots]$ de tanta claridad de belleza». Su queja, realizada sin máxima amargura, siempre ha sido ésta: la soledad, la incomunicación, su incapacidad para sentirse feliz.

Borges se presenta como el personaje que no corresponde a la situación, como el hombre que ha llegado al lugar que no le corresponde, y ese lugar que es Mallorca es sitio ideal para seres felices, es algo así como el paraíso terrenal. No necesita describir el paisaje, lo ha pintado en pocas palabras; más que dar la sensación física ha mostrado las consecuencias de esa sensación: «Mallorca es un lugar parecido a la felicidad.» Aguas celestes y transparentes, hermosos y viejos olivos, cielos límpidos, hermosas montañas abigarradas de verdor o empenachadas de nieve, quietos poblados (por aquellos años), donde la agitación de vivir es desconocida, los puede imaginar el lector; lo fundamental es la sentencia rotunda de ese joven: «un lugar parecido a la felicidad».

Pero en medio de esas frases sobre el encanto de la isla, sobre lo maravillosamente que ha sido dotada por la naturaleza, deja caer algunas características básicas de su idiosincrasia. Reflexiona: «no he poseído casi nunca el caudal de felicidad que uno debe llevar adentro para sentirse espectador digno (y no avergonzado) de tanta claridad de belleza». Establece la necesidad de un equilibrio entre belleza de paisaje y belleza de espíritu. O da significado de felicidad a la belleza. El, al no ser feliz, salvo ese "casi nunca», se siente indigno de la contemplación de la hermosura mallorquina. Se avergüenza ante $\tan$ rotunda belleza. Como el que acude, pobremente vestido, a una fiesta propia del más agresivo lujo.

Solamente a la mitad del poema aparece lo que se podría denominar confesiones de un visitante. Cuando declara: «Dos veces he vivido en Mallorca y mi recuerdo de ella es límpido y quieto.» Esa viva y hermosa naturaleza que cautivó a pintores y escritores de diferentes épocas y naciones quedó hondamente grabada en la memoria de Borges, en 1980, cuando volvió por tercera vez y recorrió algunos de los lugares que había visitado en su juventud; demostró ser dueño de una gran memoria, podía hablar de sitios a los que había visto solamente dos veces y hacía más de medio siglo. $\mathrm{Y}$ es interesante reparar en el término "vivido», no utiliza el verbo «visitar», aunque la segunda estancia fuera bastante breve, sobre todo en comparación con la primera.

Entra luego en una más pormenorizada referencia: «unas tenidas discutidoras con los amigos». Se está refiriendo a aquellas interminables tertu- 
lias que se iniciaban al mediodía en el «Café de los Artistas» ${ }^{4}$, y que, tras una pausa al caer la tarde, continuaban en los salones de una casa de prostitución, la más célebre de este siglo en la isla, "Casa Elena», que le inspiró una crónica ultraísta ${ }^{5}$ que tituló con el mismo nombre del lugar. Conversaciones en las que el tema central era la poesía, en las que la vitalidad la daba el ultraísmo que Borges había traído de la península, y en la que eran aplicados oyentes, camaradas discutidores, bohemios todos, jóvenes poetas isleños como Jacobo Sureda, como los hermanos Alomar, como los Vives, que dirigían la revista Baleares, donde el argentíno publicó poemas y su poco conocido manifiesto ultraísta.

Señala inmediatamente: «Una caminata madrugadora que empezó en Valldemosa y se cansó en Palma.» Cuando los Borges llegaron a la isla se alojaron en el hotel Universal. Ahí quedó doña Leonor Acevedo de Borges y su hija Norah. El padre marchó a la Argentina, y el hijo, Jorge Luis, tres o cuatro meses después de vivir en la capital de la isla, aceptó la invitación de Sureda y fue a vivir en ese hermoso palacete, con tanta historia, que su familia tenía en Valldemosa. Era el mismo donde había estado alojado Rubén Darío y que fuera escenario de una de sus más recordadas borracheras. La caminata a que hace referencia pudo ser, por simple humorada, que él y su amigo Jacobo, o los dos y otros amigos, desde Palma habían ido a Valldemosa. O pudo ser la necesidad de contemplar el paisaje melancólico de la noche mallorquina recibiendo el baño plateado de la luna. $Y$ tras cada paso en dirección a Palma, un nuevo concepto sobre lo que es el verso, sobre lo que representó el expresionismo, sobre lo que estaba significando el ultraísmo. Hasta que, extenuados de andar y charlar, llegaron a ciutat de Mallorca dispuestos a sueño reparador.

Borges, aunque casado dos veces, clamó en muchas oportunidades por ese amor que nunca llegaba. Parecía ya resignado a no encontrarlo jamás hasta la aparición de María Kodama y su matrimonio con ella. Pero estos dos matrimonios se produjeron después de haber transpuesto la sesentena. Anteriormente, de su juventud es poco lo que se conoce en el terreno sentimental. Hay exegetas que indican dos o tres enamoramientos, pero sin precisar, sin dar nombres y lugares. El, en su «Mallorca», nos dice, sin rubores, con una adorable sinceridad: «Una niña rosa y dorada de la que estuve enamorado tal vez y a la que no se lo dije nunca.» $\mathrm{El}$ amor siem-

\footnotetext{
${ }^{4}$ Café que estaba situado en la arteria más céntrica de Palma, el Passeig del Born, y que desapareció en los años treinta.

${ }^{5}$ Con el nombre de «Casa Elena (Hacia una estética del lupanar en España)», publicó una crónica de carácter ultraísta en la revista madrileña Ultra, en 1921.
} 
pre fue una muralla para él. Tal vez sería mejor decir: la comunicación del amor. Es muy claro en «denunciarse», al decir "estuve enamorado», «no se lo dije nunca». Se ignora si esto ocurrió durante la primera estancia o durante la segunda. Posiblemente fue en esa primera ocasión, cuando se reunía con un grupo de jóvenes mallorquines, recorría la isla, hacía una vida más social y disponía de mayor tiempo para conocer gente. La segunda visita fue contabilizada en días y no en meses, aunque esto no descarta la posibilidad de ese amor que pudo haber sido. Lo interesante es que la imagen de esa «niña rosa y dorada» no reaparece en su obra posterior a 1923. Como ocurre con ese otro amor argentino, que se produce en 1922, y determina varios poemas de su primer libro Fervor de Buenos Aires. Años después, posiblemente a partir de 1924, ya no la vuelve a mencionar ${ }^{6}$.

Por último, señala: «Unos días largos remansándose en el cálculo de las playas.» En algunas oportunidades ha indicado que era un buen nadador, lo que hace pensar que en las aguas de Mallorca se sentía feliz, aunque también ha indicado que en la quietud de esas aguas se convertía en un gran nadador, por lo fáciles que le resultaban ${ }^{7}$. Y cierra la confesión, poema, artículo, diciendo: "Ahora dejo de escribir y sigo acordándome.» Frase que encontrará equivalentes en muchas oportunidades en el largo camino de su obra. Magnífico punto final, con huellas de surrealismo e impronta rotundamente borgeana. A través de ella vemos al joven que siempre fue viejo o al viejo que impresionantemente rejuvenece, ya no importa su rostro, ya no importan si sus manos temblorosas, si su mirada perdida, lo vemos con las manos estiradas, quieto el lápiz, en blanco el resto del papel. Absorto, embebido en el recuerdo de ese paraíso del cual se considera indigno, pero no avergonzado, lo vemos satisfecho de confesar, de haber hablado de amigos, de paisaje, de una muchacha que lo condujo a la emoción, de playas y noches bajo la luna. Satisfecho, viendo pasar todo lo demás, que vivió y nunca dijo ni dirá.

${ }^{6}$ En el libro de Jean de Milleret Entrevistas con Jorge Luis Borges, el escritor argentino confiesa que estuvo enamorado de una chica argentina en 1922, pero que, a la vuelta de su viaje por Europa, la halló insignificante y no continuó con ella. No obstante esas declaraciones un tanto displicentes, por cartas a su amigo mallorquín Sureda, fechadas en 1922, se sabe que el enamoramiento alcanzó un alto grado de temperatura, al extremo de que Borges pensaba contraer matrimonio con ella.

${ }^{7}$ «Recuerdo haber sorprendido a los mallorquines con mis habilidades de nadador. Aprendí a nadar en ríos veloces como el Uruguay y el Ródano, en tanto que los mallorquines están acostumbrados a un mar quieto y sin olas» (de "Autobiographical notes», op. cit.). 